\title{
«No me enseñes más postales»: ética compensato- ria del turismo y simbólica de la desaceleración
}

\author{
«Don't show me any more postcards»: Compensatory Ethics \\ of Tourism and Symbolism of Slowdown
}

ALICIA M. DE MINGO (Universidad de Sevilla)

Artículo recibido: 22 de marzo de 2020

Solicitud de revisión: 18 de mayo de 2020

Artículo aceptado: 27 de octubre de 2020

De Mingo, Alicia M. (2020). «No me enseñes más postales»: ética compensatoria del turismo y simbólica de la desaceleración. Recerca. Revista de Pensament i Análisi, 26(1), pp. 134-153. doi: http://dx.doi.org/10.6035/Recerca.2021.26.1.7

\section{Resumen}

Desde cierto punto de vista, es indudable que el turismo de masas forma parte $-\mathrm{y}$ es expresión- de la aceleración contemporánea. Sin embargo, aquí defendemos que el deseo de diferencia - el cual anida originariamente en el sueño de viajar, antes de la aparición del sujeto como turista - responde a un deseo de desaceleración. Este deseo actúa, en el tiempo de pausa y excepción de la experiencia turística, como generador de una simbólica $-\mathrm{o}$ un imaginario- que busca preservar, proteger, restaurar y promocionar la diferencia, lo real, lo local, el pasado, la tradición, el folklore, la naturaleza, el otro... más allá del debate - ya insuficiente- en torno a la autenticidad. De este modo, se podría mostrar la importancia de rescatar al turismo de la mera mercadotecnia y comenzar a pensarlo desde su relevancia para las humanidades y su compromiso ético.

Palabras clave: turismo, experiencia, desaceleración, humanidades, ética.

\section{Abstract}

From a certain point of view, mass tourism is undeniably part - and an expression - of contemporary acceleration. However, what we defend is that desire for difference - which originally nestles in the dream of traveling, before the appearance of the subject as touristresponds to a desire for slowdown. In the time of pause and exception of the tourist experience, this desire acts as a generator of a symbolism - or an imagery - that seeks to preserve, protect, restore and promote difference, reality, localness, past, tradition, folklore, nature, the other... beyond the - already insufficient - debate on authenticity. In this way, the im- 
portance of rescuing tourism from mere marketing could be shown, as well as to start to think about it from its relevance to humanities and its ethical commitment.

Key Words: tourism, experience, slowdown, humanities, ethics.

\section{INTRODUCCIÓN}

No me enseñes más postales.

Si no están ellos,

si no estás tú,

si falta todo lo que es verdad,

si no cuentan,

si no inspiran,

si no huelen,

si no saben,

si no le hacen justicia

a la vida que te espera aquí.

No me enseñes más postales.

Si no cabe nuestra luz, si no cabe nuestra paz,

si no cabe nuestro mar, si no cabe nuestra vida.

No me enseñes más postales.

\section{Comunitat Valenciana, \\ Mediterráneo en vivo. ${ }^{1}$}

Esclarecer la fructífera paradoja que se produce entre la aceleración global contemporánea - a la que también contribuye el turismo-y, por otra parte, la demanda simbólica de desaceleración, tal como dicha paradoja se encarna en el fenómeno del turismo, es el propósito esencial de esta contribución. Cuando en el texto publicitario que preside nuestro título se solicita que no se nos enseñen más postales, se está apelando — con eficacia- a una simbólica de

1 El texto se corresponde con las diferentes versiones de los anuncios publicitarios que en el 2016 se emitieron para promocionar el turismo en la Comunidad Valenciana, bajo el lema «No me enseñes más postales / Mediterráneo en vivo», que he conjugado de modo no literal, atendiendo a la idea esencial que se busca transmitir en la campaña, de la agencia publicitaria Rosebud. Recuperado de: https://www.youtube.com/watch?v=_4UnLU2RJ1U [Consultado el 14 de marzo de 2020]. 
la desaceleración que apunta a la realización del viaje, al estar allí, a la demora en el encuentro real con el destino turístico, algo que las postales nunca podrían sustituir.

La investigación que proponemos abordará el proceso imaginario de ruptura de la aceleración que tiene lugar en la intimidad del deseo de viajar; a continuación, el modo diverso, a título ejemplar, en que se produce la apertura de ámbitos de excepcionalidad compensatoria — de desaceleración- por parte de la actividad turística, para finalizar atendiendo a algunas de sus implicaciones éticas y humanistas.

Nada más entrar en el microuniverso de Plataforma, de Michel Houllebecq, aparece parte del drama del turismo. Para su protagonista,

Mis sueños son mediocres. Como todos los habitantes de Europa occidental, quiero viajar. Bueno, hay que tener en cuenta las dificultades, la barrera del idioma, la mala organización de los transportes de grupo, los peligros de volar y de que a uno le estafen; para decirlo en plata, en el fondo lo que yo quiero es hacer turismo. Cada cual tiene los sueños de los que es capaz, y mi sueño es encadenar al infinito los «Circuitos de la pasión», las «Vacaciones en color» y los «Placeres a la carta», por mencionar los temas de tres catálogos de Nouvelles Frontiéres (Houllebecq, 2002: 31).

No compartimos la opinión de que en el fondo del deseo de viajar esté el deseo de hacer turismo. Es más bien al revés: se puede viajar sin hacer turismo -no me refiero a la oposición entre viajero y turista-, pero no querer hacer turismo sin el deseo de viajar, que surge mucho antes y diríamos que en una zona lejana de lo que conocemos y nos figuramos como turismo. Que el viajar deba recurrir al turismo no habría de afectar a su deseo y a su prestigio, por más que en cierto momento, muy temprano, la mayoría nos percatemos de que para viajar se torna necesario - siquiera como mal menor- hacer turismo. No deberíamos, en todo caso, confundir deseo de viajar con turismo, ni aprestarnos a caer, sin oponer apenas resistencia, bajo la amenaza de la decepción, como no es infrecuente que suceda cuando el deseo acepta el desafío de lo real.

\section{ENSOÑACIÓN, IMAGINARIO Y NEOEXPERIENCIA. EL DESEO DE VIAJAR}

Más allá de cualesquiera otras posibles explicaciones, lo que quizás más originalmente mueve al turismo en el orden motivacional, pues primeramente conmueve al futuro turista, antes de que realice desplazamiento alguno, y qui- 
zás constituye su verdad primera, se encuentra muy lejos - y solemos olvidarlo- de lo que conocemos como industria turística. Contra las apariencias -abarrotadas de estereotipos, populares y académicos-, la verdad profunda del turismo no se deja comprobar sobre todo como comportamiento visible y gestionable. Dicha verdad no sería fácil de ubicar, pues escapa con facilidad a la retina, por más que nuestra usual precomprensión del turismo como turismo masivo nos haga considerar su realidad desde clichés visuales que creemos reconocer fácilmente y que se corresponden con un mundo inmenso y, sin duda, desde el punto de vista de la industria turística, con un potencial enorme de rentabilidad.

Y, sin embargo, para siquiera entrever la fuente primera de esa rentabilidad, habría que remontarse a los trasfondos emocionales de un sujeto que, en lo esencial, se cansa, pero no simplemente de modo que busque un descanso físico - no es este el turista que aquí más quisiéramos destacar-, sino por hartazgo y aburrimiento de lo mismo, que le impulsa, en medida diversa, y según sus posibilidades de tiempo de ocio, económicas, etc., a desplazarse buscando lo nuevo bajo la forma de lo diverso, saliendo lejos - no solo geográficamente, sino simbólica y emocionalmente-, creyendo poder librarse, no importa si tan solo por unos días, de su atosigante, opresiva o simplemente rutinaria cotidianeidad.

Creemos que es necesario intentar comprender al turista justo antes de que lo sea, en el fondo de su deseo. A este respecto, si se trata del deseo de lo diverso, ¿no sería razonable preguntarse cómo sería posible aburrirse de lo mismo? ¿Acaso no estamos ya, en nuestra cotidianeidad, estresados por lo diferente $\mathrm{o}$, al menos, por pequeñas diferencias que excitan continuamente nuestra atención? ¿No ocurre a diario, en las grandes ciudades, que nuestros nervios son zarandeados, agotados, por mil y una solicitaciones saturantes (Gergen, 2006)? ¿Y qué decir de nuestros trabajos? ¿Es que acaso no tenemos dosis más que suficiente de diferencia y entretenimiento? Simmel se percató, en 1903, de que las individualidades urbanitas se caracterizan por el «acrecentamiento de la vida nerviosa». El ser humano, como «ser de diferencias», vive continuamente estimulado por esto o aquello, lo que suele contrarrestar con cierto intelectualismo y pagar con el embotamiento de su mente (Simmel, 2001: 376-377, 382-383). Pues bien, sometido a esa tensión, el ser humano parece no conformarse con ello, lanzándose a la «avidez de novedades» o la «curiosidad $»^{2}$ (Diego, 2014: 149).

2 Véase el importante $\$ 36$ de Ser y tiempo (Heidegger, 2016: 190-191). 
Y, sin embargo, esta avidez recoge solo cierto aspecto, de los más superficiales, de lo que en el deseo de viajar está en juego. Como urbanita, el turista no necesita precalentamiento alguno, pues se deja fácilmente motivar y movilizar, lo que explica su receptividad a la oferta de la industria cultural-turística, no importa si se trata de una escapada - de moda actualmente - o de un gran viaje. En muchas ocasiones sueña no con el reposo, sino con un extraño descanso que le inspire, más allá de su embotamiento ordinario, a costa incluso de retornar físicamente agotado, pero gratificado, habiendo podido compensar la diferencia indiferente de la estresante y al mismo tiempo aburrida cotidianeidad con una diferencia diferente, exótica —en el mejor sentido- (cfr. Segalen, 2017).

Desde el modelo de la aceleración, el turismo representa, sin duda, un signo descomunal de nuestro tiempo. Consuma el modelo del ser humano incansablemente deseante y ajetreado, en perpetuo movimiento, acosado por mil y un estímulos que le abruman, zarandeándolo y enredándolo en toda una red de emociones, promesas placenteras, promociones, ofertas... que conducen a cuestionar la posible y deseable autonomía del turista potencial -como bien ejemplifican los estudios de neuroturismo- (cfr. López-González, 2019). Sin embargo, el turista no se deja confundir con quien simplemente se mueve motivado por negocios, profesionalmente, etc. (cfr. Sloterdijk, 2010: 57). Para que podamos construir su figura y percatarnos de su capacidad de soñar es preciso pensarlo desde su tiempo de ocio, al margen de la vida ordinaria. En efecto: mucho antes de comenzar a gestionar su viaje como desplazamiento y efectuarlo, aprestándose a su disfrute, y al margen del coste económico y del desgaste corporal y psíquico de su placer fugaz, el turista sueña. Y sueña, aunque su sueño solo transcurra en el breve tiempo que lo separa de la decisión de convertirse en turista. En cierto modo, lo esencial ya se decide imaginaria y simbólicamente mucho antes del desplazamiento físico. La diferencia entre el turista móvil - modélico- y el inmóvil es que, a diferencia del que se arrellana cómodamente en su sillón frente a la televisión o con una buena guía o un cautivador libro de viajes, el primero desea ver allí lo que casi siempre, mezclado con sus sueños, ya le ha sido dado a ver, y de forma abrumadoramente abundante, en estampas y postales (Augé, 1998; Diego, 2014).

Es preciso conceder al turista una profundidad que no se deja reducir a la mera curiosidad y avidez de novedades, aunque esta describa ajustadamente el impulso de cierto turista-tipo —el más criticado y criticable, el que más desprecio suscita y el más ridiculizado en su cliché-, al que no quisiéramos reducir aquí al turista en general ni, desde luego, al turista portador de las mejores 
posibilidades de la experiencia que podría incumbirle como turista. Aunque se decida a ser y acepte convertirse en turista, este sigue debiéndose al intenso deseo de viajar, en el que se diría que venera la posibilidad de lo diferente, nuevo y lejano - no en sentido meramente geográfico-, sin cuidarse demasiado, en principio, de las mediaciones y pruebas que su deseo habrá de superar. Se verifica, de este modo, que, en su sueño, el turista desea lo Otro y al Otro y que está dispuesto a dejarse seducir por su alteridad, sin que su localidad, su pequeño mundo cotidiano, pueda agotar su inquieto deseo. Hermosa inquietud, sin duda, prueba de un sano y lúcido inconformismo. Las novedades cotidianas ya no le llenan; ni lo presuntamente novedoso de los tediosos cotilleos, ni esas pequeñas distracciones que calman ocasionalmente su curiosidad: modas, espectáculos, periódicos y estar a la última en un entorno en el que todo suele estar cómodamente en su sitio y donde todo parece ser, por lo común, comprensible, escasamente sorprendente y, menos aún, seductor ni fascinante.

En esta perspectiva, asumida estratégicamente, se ha de reconocer que el turista es más que solo turista. Muchos ensayos y estudios sobre el turismo se ceban en el turista estereotipado, al que tratan con un tono entre paternal e inmisericorde. En este sentido, el reproche que suele dirigirse a las guías turísticas y al turismo tradicional también podría orientarse contra el abuso del cliché del turista que se maneja con excesiva y acrítica frecuencia en medios críticos, presuntamente más lúcidos. Desatendido el deseo de viajar, que solo se da en el «mundo de la vida» - por más mediatizado que se encuentre-, al turista se le sobreentiende como turista, básicamente alienado en la gran maquinaria del turismo que lo ha engendrado, por ejemplo, publicitariamente. Después de todo, si se toma únicamente al turista y se desactiva lo que en él se conserva aún de aquel originario deseo de viajar, lo que queda es solo un turista mecánico. A este respecto, una ética del turismo quizá debiera comenzar nodevaluando, de entrada, al turista, tornando irrisoria su figura -inequívocamente muy rentable. Siempre solemos olvidar lo que sucede en el deseo - ciertamente, un deseo verdadero, acorde a la veracidad del sujeto para consigo, y siempre un reducto fenomenológico, más allá de la duda acerca de si es auténtico o inducido. Si no se preserva al turista, que no es solo turista, será difícil no identificarlo con las hordas de turistas que asaltan todo, como si de una plaga invasiva se tratara, dejando desolación a su paso. Por ello, se hace preciso intentar pensar al turista más acá del estereotipo que el propio turismo, sus gestores y observadores segregan y, sobre todo, sus críticos, nostálgicos, tal vez, de un elitismo del viajar que el turismo de masas, hiperdemocratizado, ha destrozado. 
Decíamos, hace un momento, que se ha de reconocer que el turista es más que solo turista. Por otra parte, en segundo lugar, no se debe despreciar que el turista va siempre de nuevas. Con frecuencia parece como si en la literatura crítica el turista hubiese quedado reemplazado, en lo que de sujeto personal e individual tiene, por una condensación de todos los turistas, favoreciéndose así la conclusión, básica en mucha literatura crítica sobre el turismo de masas, de que todo ha sido ya visto y de que en el mundo hiperturistizado «nada hay nuevo bajo el sol», ya no quedan destinos inexplorados, etc. Conclusión, bien vista, absurda, que desatiende la íntima ilusión del deseo del turista - que no deja ser singular por ser turista-, indemne frente a todos los reproches de quien desdeñosamente se empeña en recordarle que solo «descubrirá Mediterráneos» (Moreno, 2020: 177-178), salvo que hubiese debido comenzar una suerte de eterno retorno de sus viajes porque, digámoslo llanamente, ya lo hubiese visto todo y el mundo hubiese quedado encerrado, casi apocalípticamente, en un déjà vu global. Cuando se habla de la «falacia de llegar a lugares inexplorados», si bien no es del todo desacertado hablar en tales términos, sin embargo, no se hace justicia al deseo de viajar que anida en todo — ivulgar!_turista. ¿Acaso es decisivo y relevante el motivo de lo inexplorado? Augé calificó como «imposible» al viaje que podría tener aún lugar si no fuera porque nuestro mundo globalizado hubiese finiquitado toda posibilidad de lo «inexplorado». Concluía su idea sosteniendo que

viajar, sí, hay que viajar, pero sobre todo no hacer turismo. Esas agencias que cuadriculan la tierra [...] son las primeras responsables de la ficcionalización del mundo, de su desrealización aparente; en realidad, son las responsables de convertir a unos en espectadores y a otros en espectáculo [...].

El mundo existe todavía en su diversidad. Pero esa diversidad poco tiene que ver con el caleidoscopio ilusorio del turismo. Tal vez una de nuestras tareas más urgentes sea volver a aprender a viajar, en todo caso, a las regiones más cercanas a nosotros, a fin de aprender nuevamente a ver (Augé, 1998: 15-16; cfr. Verdú, 2006: 15-16).

Además, en tercer lugar, siempre se aborda con un tono hipercrítico que el turista parezca que acaba viendo lo que ya ha visto representado en estampas y postales, con lo que se haría imposible encuentro verdadero alguno. Sin embargo, es cierto que el turista desea encontrar en la realidad precisamente lo que antes veía solo como imagen, pues presiente, con razón, que aquello que ya había visto le deparará - ahora sí, a él-, en su encuentro, mucho más (Ortega y Gasset, 2017: II). Ello no significa que a ese encuentro no lo amenazase la 
posibilidad de la decepción o la impresión de fraude. En todo caso, a este respecto, ¿alguien se animaría, de veras, ante la posibilidad de, por así decirlo, una cita a ciegas? Cualquiera reconocería que siempre vamos a buscar algo que ya hemos siquiera presentido, o que se nos ha anunciado, anticipando su presencia. Presencia, pues, es lo que desea el turista —más allá de quien solo sueña viajar- más allá de suplencias, sustituciones y suplantaciones.

De este modo, comprobamos la importancia — en nuestro caso, para una ética del turismo- de tomar al turista por sí mismo. No olvidemos, pues, que: a) siempre es más que solo turista, $b$ ) va/viaja siempre de nuevas, y c) buscando que se plenifiquen para sí mismo las postales. Nos situaríamos, de este modo, en una perspectiva de personalización del turista, evitando al máximo no solo su estereotipificación, sino también su estigmatización, sin reducirlo a su mera realidad sociológica y mercadotécnica.

No es una hipótesis absurda: en su sueño de viajar, el turista es solo posible como turista ex novo e ilusionado. Sería difícil negar que, en el fondo, también es romántico y aventurero. No va simplemente a hacer un viaje, sino a realizar una experiencia de encuentro, y no importará demasiado que sea o se le tome por un ingenuo tutorizado o guiado. El momento de la expectativa de experiencia es decisivo. Por más que haya surgido en los últimos tiempos justamente un «turismo de experiencias» (Quinlan Cutler y Carmichael, 2010), viajar siempre supuso la posibilidad de nuevas experiencias a todos los niveles: cognitivo, emocional, estético, ético, interpersonal, intercultural, etc. La novedad que incumbe al deseo es, en términos difíciles de precisar, la propia de una neoexperiencia enfrentada a un repertorio de posibilidades inmenso. Que haya surgido la posibilidad del turismo posturismo era más que previsible. A nuestro juicio, lo que estaría en juego no es tanto la autenticidad, cuanto la experiencia de lo diverso - como ruptura de lo cotidiano (Cohen, 2005: 17-19; MacCannell, 2003). Por ello insistíamos, al comienzo, en la exigencia de lo diverso por parte del turista y en la demanda de otra diferencia en la huida del embotamiento cotidiano-existencial. Después de todo, la demanda de autenticidad es aún demasiado moderna, como réplica de lo falso, el simulacro, etc. Por su parte, la demanda de diferencia, sin embargo, se mantiene como compensación frente a lo que Baudrillard llamó el «infierno de lo Mismo» (Baudrillard, 1991), aunque el pensador francés no confiase, en sus posiciones radicales, maximalistas, en que realmente fuese posible, hoy, escapar a ese infierno.

Narciso -el soñador - hace las maletas. Una vez más, es preciso reconocer que el turista, primero, sueña: no le importan tanto las realidades que habrá de encontrar, en cuanto realidades, como sus sueños, en incontables formas ex- 
presivas. Hay mil y una opciones, a la carta, que hacen absurda, como decíamos, la idea del agotamiento del filón de los destinos. Inabordables, si hubieran de ser todos: ruinas, paisajes, costumbres, comidas, olores, atardeceres, arenas de playas..., pero todos accesibles. Llegamos a comprender, así, cómo se entrelazan destinos, ámbitos y experiencias. Ciertamente, el turismo puede apropiárselo todo: desde los paisajes que aparecen en una serie televisiva hasta viñedos y bodegas —enoturismo-, naturaleza - ecoturismo-, slum tourism (Frenzel, Koens y Steinbrink, 2012), turismo de arqueología industrial, incluso de museología filosófica (Arcos Pumarola, 2016), etc., y se puede dejar orientar también por motivos que entrañan prácticas deleznables, como el turismo sexual, o de dudosísimo gusto, como el de botellona.

El turismo es una decisión vivida como libre para abrir, ampliar, diversificar... más allá de la cotidianeidad. El soñador y el turista son expresiones perfectas del narcisismo contemporáneo, que tan bien describiera Lipovetsky en los ochenta, aún con plena vigencia (Lipovetsky, 1986; cfr. Bauman, 2009: 279285). Cualquier monitorización del deseo habrá de pasar por el tamiz del imaginario narcisista del turista. Hay donde elegir, y resulta alucinante la diversidad: de las Azores al Kalahari, de Katmandú al altiplano boliviano, del lago Ness al Coliseo romano, de la Quinta Avenida a la Patagonia, de Dubai a Islandia..., pero también de los restos de una vieja fábrica a un monasterio, de unos acantilados noruegos a la torre Eiffel... El turista presiente, sin que a veces se percate de ello, que, en sus sueños, el viaje que proyecta se parece a él, pero no a él en su vida ordinaria, sino una dimensión de sí que no es plenamente transparente ni unívoca. Nos buscamos a nosotros mismos a través de nuestros sueños de viajes y allá lejos, luego, como extraños (Diego, 2014: 198 y ss.).

\section{HOMO COMPENSATOR}

Según la perspectiva que quisiéramos defender aquí, el fenómeno del turismo, al menos de un cierto ideal y práctica del mismo - no poco relevantes-, congrega, quizás paradójicamente, el trajín y bullicio que hoy parece inevitable al turismo y, por otra parte, la búsqueda de experiencias, vinculadas a destinos, de una suerte de desaceleración del mundo. No es descabellado imaginar que, de este modo, el mundo según el turismo puede tornarse un reservorio del imaginario de la desaceleración a la que ya, ciertamente, perte- 
nece la experiencia del viaje no, desde luego, en la agitación de sus preparativos y realización, sino, antes y más profundamente (en el fondo del sueño de viajar), como pausa (lo que todo ocio supone) y como excepción, en la medida en que al turista le es concedida como oportunidad vivir su experiencia como compensatoria del ajetreado contínuum de una cotidianeidad presionada por exigencias de celeridad, progresismo, rendimiento, competitividad, pragmatismo, hipercomunicación, banalización, uniformización, consumismo, etc. La pausa y la excepción podrán ser figuradas, al menos simbólicamente, como escapada, término que traduce bastante adecuadamente la cualidad del deseo de viajar, de estar en otra parte. Los sueños que surgen en el deseo de viajar rezuman lo que podríamos llamar excepcionalidad compensatoria frente a las presiones a las que nos referíamos anteriormente y que podrían resumirse como vida acelerada, que tan bien reflejó Godfrey Reggio ya en 1982 en Koyaanisqatsi, por medio del time-lapse. Se recordará que ese término significa en lengua hopi 'crazy life, life in turmoil, life out of balance, life disintegrating, a state of life that calls for another way of living'.

La excepción/pausa forma parte consubstancial de lo que interiormente vive quien sueña con viajar. Sí, hay un turista que sueña con desacelerar, aunque para realizar su sueño deba someterse a innumerables estreses. Por eso, el turismo es un potenciador de lo diverso-desacelerante, con lo que compensa la uniformización acelerada del mundo, con sus enormes pérdidas. ${ }^{3}$

La guía es, así pues, la búsqueda de lo diverso, nacida en los adentros del deseo - sin que sea necesario, en el nivel descriptivo, que nos preguntemos aquí, y por el momento, por sus motivaciones ocultas, sus presiones y condicionamientos, etc. Ha de conducir lejos (dicho deseo), pero este «lejos» no debe ser necesariamente interpretado en sentido espacial, sino más bien experiencial. Lejos, también, habría de conducir el deseo del nostálgico hacia lo que siente como perdido y ausente.

Ya el deseo de ir allí es una apuesta por a) lo real. Pasando del sueño a la realidad, el turista ha de confiar, más que temer, que las expectativas quedarán al menos relativamente satisfechas. Apostar por lo real en un mundo de intercomunicaciones velocísimas y crecientemente virtuales, en el que los simulacros fluyen, ¿no implica una simbólica de la desaceleración? Se necesita paciencia y, en el fondo, la virtud del encuentro. El turista apuesta por lo real

\footnotetext{
Lo que se conoce en la actualidad como slow tourism (Babou y Callot, 2009; Moira, Mylonopoulos y Kondoudaki, 2017) viene a mostrar paradigmáticamente esa demanda de desaceleración en su modalidad vivencial más fehaciente y no ya meramente simbólica o cultural, sino de facto.
} 
con toda su riqueza y espesor, así como por posibilidades que solo lo real podría hacer fructificar. La realidad que se espera encontrar no se separa de ser realidad verdadera y auténtica. Incluso para los más escépticos, una semirrealidad allí será más que una estampa aquí. Esta debe obrar como quizás un primer medio de transporte. De aquí el lema que nos sirve como guía: «No me enseñes más postales».

Del mismo modo, al desplazarse hacia lo real-allí, el turista provoca el tránsito desde la accesibilidad de lo global («el mundo a nuestra disposición») hasta la atracción y fascinación de b) lo local, que el turismo favorece (Salazar, 2005: 144-146). De este modo, el turista avala una globalización que recoloca por doquier, fundándolos, lugares que deben poder ser reivindicados por su singularidad, justo en el lado opuesto de la uniformización de la globalización - potencialmente devastadora, desanimante de cualquier búsqueda de lo diverso (Verdú, 2006: 15-26). El turismo hace realidad una globalización multilocalizadora, y no en el sentido específico de la glocalización —según la cual lo global encuentra el modo de ajustarse a lo local-, sino provocando el reconocimiento de lo local-diverso. El metarrelato inagotable de la globalización, vinculada a la comunicación y la interferencia, se combina, de este modo, con el fin $-\mathrm{o}$ al menos moratoria- de los metarrelatos por lo que se refiere al surgimiento de incontables focos de significación y atracción locales, compensando así, al menos en parte, los efectos negativos de la uniformización. Si atendemos al ejemplo propuesto por Salazar (2005: 142-143), por lo que se refiere al cultivo del arroz en Java, la localización aspira a mostrar al turista el modo tradicional de cultivo del arroz, mientras que en la vida cotidiana dicho cultivo está completamente mecanizado. Lo local puede ser muy distante (Java) o próximo (Comunidad Valenciana). El turismo potencia, así pues, el enclave in situ, lo que, por lo demás, es esencial al turismo como potenciador económico local. Así pues, a diferencia de la velocidad y del recorrido de las distancias que introduce el mundo meramente representado telemáticamente, cuando el turista se decide a hacer realidad su desplazamiento apuesta por experiencias de algún modo imaginariamente lentas, demoradas y comprometidas corporalmente. Por otra parte, la experiencia in situ favorece situar encarnadamente lo local en su contexto y, en el mejor de los sentidos, en su multidimensional plenitud, que será vivida como oportunidad de conocimiento y disfrute. Ir-allí, más allá de las postales, permitirá acceder no solo a lo que la postal muestra, con su pobreza de medios meramente representacionales, con su efecto premonitorio. Allí, también, el turista podrá ser acogido y participar sin pertenecer. Será preciso, entonces, que el turista no sea considerado, ni 
se considere a sí mismo, meramente como cliente en un dispositivo de rentabilidad económica. Esta es una experiencia decisiva, por lo que exige a todos (quienes visitan y quienes acogen) una capacidad de empatía y deleite, que es, a su modo, también desacelerante.

El turismo funciona a doble banda: por una parte, con la globalidad en un horizonte de cuasi omniaccesibilidad. Por otra parte, trabaja con el atractivo, en lo global, de lo local. A diferencia de la orientación a lo local de los movimientos conservadores y retráctiles, con claras pulsiones autoidentitarias, lo local que implica al turismo, y que este puede promover, es lo local del Otro por sí mismo, a partir de su irreductibilidad a lo global, como afirmación de una idiosincrasia. El turista debe aprender a reconocer el derecho a la convivencia entre lo local y lo común, entre el pasado y el presente.

Si la uniformización se compensa con la diversidad y la singularidad - recordemos que se trata del ir y venir entre ensoñación y realidad-, lo cotidiano, ya conocido y familiar, y por tanto desgastado, se compensará con la fascinación ensoñadora por c) lo original-auténtico. Sin embargo, es necesaria a este respecto cierta precaución en torno a la demanda de autenticidad, sobre la cual se constata fácilmente toda una obsesión, bien repartida entre usuarios y proveedores, gestores, intérpretes del fenómeno turístico y, especialmente, entre los críticos, que suelen cebarse en lo que les parece, y en ocasiones no sin razones, que puede llegar a ser una aspiración pueril de los turistas. A efectos de comprender la crítica, bastaría atender a la constatación del poder contemporáneo de la simulación como precesión de los simulacros, desde finales de los setenta del siglo XX (Baudrillard, 1987: 7-80). Dean MacCannell alentó enormemente esta vía crítica (Aramberri, 2011: 131 y ss.), cuando denunció en 1976 lo que llamó «autenticidad escenificada» (MacCannell, 2003: 121 ss.), y más tarde especificó como «etnicidad reconstruida» (MacCannell, 1988: 221-226). Se afirma, no sin razón, que el que sueña con viajar espera encontrar in situ una realidad auténtica, pero muchas veces solo encuentra un remedo, una suerte de sucedáneo o escenificación realizada ex profeso para los turistas. En la época en que se tornó candente esta cuestión era un problema importante, desde una perspectiva no solo sociológica, sino ética, porque gracias a esa autenticidad escenificada o etnicidad reconstruida parecía poder someterse a ciertos pueblos y etnias, en origen, a cumplir una serie de exigencias que les impedían evolucionar dinámicamente, como cualquier sociedad viva, en virtud de tener que satisfacer las expectativas del turista. Sin embargo, creemos que esta cuestión crítica ha perdido en la actualidad parte de su original vi- 
gencia, pues el turista comprende que en los lugares de destino la vida prosigue y es imposible vivir en el pasado.

Se trata de una cuestión relevante, a la que casi toda la literatura suele conceder mucho crédito (Diego, 2014). ${ }^{4}$ Bien visto, cabe imaginar que un turista suficientemente lúcido sabría reconocer la autenticidad de modo que, aunque comprendiese que es reconstruida, no le decepcionase, pues la reconstrucción no implica falsedad ni engaño, especialmente si se la presenta como lo que es (Rivera Mateos, 2012: 182-183). ¿No es el compromiso del turista propiamente y sobre todo con la diversidad, más que con la autenticidad? En efecto, la ensoñación parece demandar realidad, pero ¿no es más intensa la demanda de diferencia, que el turista pide que se cumpla, pasando la pregunta por la realidad auténtica a un plano secundario? Esta cuestión guarda relación con la hipotética exigencia -imaginémosla, por reductio ad absurdum-de que al entrar en una ermita o en una catedral no hubiese luz eléctrica, pues, de haberla, se deformaría la realidad/autenticidad originaria... En verdad, los turistas ya saben sobradamente que no se puede viajar en el tiempo y que para eso disponemos de vestigios, huellas, ruinas, museos..., pero también tradiciones vivas, etc.

Quizás uno de los aspectos en que mejor se aprecia el carácter compensatorio desacelerante del turismo sea en su d) protección del pasado. Respecto a la compensación en general, y especialmente en un sentido histórico, nos ha enseñado mucho Odo Marquard a mediados de los ochenta. En lo esencial, Marquard consideraba que los procesos de modernización introducen una aceleración cultural que sería insoportable y desastrosa de no ser porque esos procesos fuesen compensados. Había propuesto como centro de su crítica lo que denominaba «extrañamiento tacógeno del mundo» (Marquard, 2001: 95), de modo que le parecía esencial la figura antropológico-filosófica del Homo compensator. A este respecto, asignaba a las ciencias del espíritu — hoy diríamos las humanidades - la capacidad y la responsabilidad de ofrecer esa compensación. Pues bien, consideramos que el turismo supone actualmente una suerte de rama o vertiente de las humanidades, y que no simplemente debería estar vinculado institucionalmente - al menos en ciertos campus universitarios lo

\footnotetext{
Confiesa Gergen su decepción cuando lo que creía — románticamente- que era la vestimenta real y auténtica de la gente en un pueblo de Tailandia se convirtió en motivo de negocio para los lugareños cuando comprobó que esa vestimenta no era la expresión espontánea de su yo, sino de su sagacidad comercial, en referencia al modo en que las subculturas que aportan motivos turísticos se dejan guiar por estos motivos. Véase, para la anécdota completa, Gergen, 2006: 303-304.
} 
está-, con las finanzas. ${ }^{5}$ Marquard piensa que «la modernización [...] causa pérdidas en el mundo de la vida a cuya compensación contribuyen las ciencias del espíritu» (Marquard, 200o: 113-114). Uno de sus lemas preferidos es el de que, en el horizonte de la modernidad,

cada vez menos de lo que era pasado parece poder tener futuro; los mundos históricos de procedencia corren cada vez más el peligro de envejecer. Sin compensación, esto sería una pérdida humanamente insoportable, pues cada vez se satisfaría menos la necesidad humana de vivir en un mundo con colorido, confianza y sentido (Marquard, 2000: 115-116).

Según Marquard, a las ciencias del espíritu les compete esa compensación simbólica, con un fuerte componente ético, en la que se han de recuperar los «mundos de procedencia», para lo que las ciencias del espíritu disponen de «historias de sensibilización», «historias de preservación» e «historias de orientación». Aunque son interesantes las tres, quizás nos incumban más las dos primeras. Marquard no nombra al turismo, pero parece referirse a él justamente tal como aquí intentamos pensar una de sus expresiones. Respecto a las dos primeras historias, dice:

Historias de sensibilización. Aquí se trata, como compensación a un mundo que va perdiendo color, de la necesidad de color por parte del mundo de la vida. La modernización opera como «desencantamiento»-Max Weber-; este desencantamiento moderno del mundo queda compensado, de una manera moderna, mediante el encantamiento sustitutorio de lo estético: el arte estético-autónomo no había existido antes. Por ello surge, de una manera específicamente moderna, el sentido estético, cuya tarea compensadora apoyan las ciencias del espíritu al contar historias de sensibilización. Las ciencias del espíritu cuentan.

Historias de preservación. Aquí se trata, como compensación a un mundo que se ha vuelto extraño, de la necesidad de familiaridad por parte del mundo de la vida. La modernización opera como artificialización acelerada, es decir, como desnaturalización, y como objetivación, es decir, como deshistorización de la realidad; ambas quedan compensadas, de una manera específicamente moderna, mediante el desarrollo de la sensibilidad hacia la naturaleza - desde el descubrimiento del paisaje hasta los parques naturales- y mediante el desarrollo de la sensibilidad para la historia con sus actividades conservadoras: el museo, el recuerdo investigador, los monumentos. De este modo, la sociedad de los portadores de bata - precisamente ella - es al mismo tiempo la sociedad de los cuidadores de plantas y de trajes. Ninguna época ha destruido tanto como la Modernidad; ninguna época ha preservado tanto como la Modernidad: mediante el desarrollo de habilidades

\footnotetext{
5 En este mismo sentido, es de destacar que en el Glosario para una Sociedad intercultural que editó Conill en el 2002 no se incluyera la entrada «Turismo».
} 
para llevar consigo cada vez más pasado al futuro. Por ello surge — de una manera específicamente moderna- el sentido histórico y, desde Rousseau, el sentido ecológico, cuyas tareas de compensación apoyan las ciencias del espíritu al contar historias de preservación (Marquard, 2000: 117).

Marquard, en efecto, no nombra el turismo como vector de compensación, pero basta leer su propuesta para comprender en qué medida sería necesario que turismo se vinculase con humanidades, siempre y cuando fuésemos capaces de alcanzar cierta sensibilidad comprensiva para conciliar el ajetreo de la industria turística con esa dimensión del sueño de viajar de que hablábamos al comienzo. La suerte del turista es que puede educarse en combinar esta sensibilización y preservación al mismo tiempo desplazándose, visitando otras culturas... y, en todo caso, alcanzar un sentido de extrañamiento muy fructífero, que se puede apreciar en la visita a una exposición de Las edades del hombre que tuviese como motivo, como en el 2019, a los ángeles, o en la visita a una vieja explotación minera o, más lejos, en la asistencia a una sesión de danza de derviches giróvagos en un barrio periférico de Estambul, o incluso en un local, pensado para turistas, en el centro de la ciudad.

\section{POR UNA ÉTICA DEL TURISMO}

Para un sujeto ávido de novedades, el deseo de viajar aporta un matiz diferencial decisivo. Quizás hubiera de ser en él donde una ética del turismo, ${ }^{6}$ preocupada sobre todo por la formación humana, y nos atreveríamos a decir que humanista de quienes se involucran en la industria turística, debiera encontrar su más firme punto de apoyo, en la medida en que se dejara presentir en dicho deseo todo lo importante que el turista espera - aunque quizás no lo encuentre de hecho- y que, a su vez, espera del propio turista quien habrá de recibirle.

Mucho antes que a la industria o al negocio, la ética del turismo debe proteger ese deseo de viajar y el ideal que involucra, ideal que implica mayoritariamente el deseo de encuentro interhumano que, si bien no necesariamente ha de aparecer de inmediato, siempre comparece a la postre. Casi nos atreveríamos a decir, por más que pueda parecer excesivo, que a la ética del turismo se le ha de encomendar que una cierta expresión de lo debido proteja la que es, sin duda, una de las oportunidades más extraordinarias - no únicamente ren-

\footnotetext{
${ }^{6}$ Cfr. para una visión general e histórica de las relaciones entre ética y turismo, Fennell, 2006.
} 
tables- que ofrece la globalización, a fin de evitar que sea malversada, sometiendo a valoración y escrutinio tanto los fines como los medios (Rivera Mateos, 2012), cuya lucidez primera $-\mathrm{y}$ a veces ingenua - radica en el sueño de viajar, milenario y actualísimo, y, de inmediato, como si se tratara de articular y dar expresión a ese sueño, en los imaginarios que lo guían (Amirou, 1995) y en los medios de que dispone para acreditar que pueda desplegarse.

Tal es la idea esencial. La fascinación por lo real, la autenticidad, lo local y el pasado, que el turismo es capaz de mediar, proteger y favorecer, es compensadora. Es cierto que las identidades se dejan conservar y promocionar por un turismo que busca el apoyo de tradiciones, folclore o fiestas populares... en un mundo velocísimo, global y uniformizador, y a veces banal. Por su parte, el ecoturismo y el agroturismo promocionan una creciente sensibilización en el respeto por la naturaleza, la revalorización de la vida rural, etc. (Martínez Quintana, 2017). Lo Otro no es solo lo lejano, sino aquello cuya pérdida se lamenta... y que inspira al turista, aunque solo sea posible su contacto fugazmente. La brevedad de su experiencia se verá compensada, en muchos casos, por la dosificación de las oportunidades de nuevos encuentros. Desde esta perspectiva, incluso el acto de fotografiar, tan usualmente despreciado -frente a la atención viva a lo real-, también tiene un poder de compensación y de preservación del pasado, digno de aprecio.

Sin pretender restarle su relevancia, pensamos que el gran tema para una ética del turismo, al menos en cierta dimensión de esa ética, no ha de ser el de la autenticidad, que favorece una hipercrítica poco fructífera, especialmente cuando su exigencia casi se torna fundamentalista; sino que se debe, sobre todo, a la defensa y promoción de lo diverso. Ojalá todos los turistas que lo desearan pudiesen visitar las cuevas de Altamira o asistir a una danza auténtica de derviches giróvagos. Entretanto, disponen del museo de Altamira y de espectáculos de derviches que no habría que despreciar por no ser auténticos. Lo decisivo transcurre en dirección a la interioridad del sueño de lo diverso no simplemente como placer y diversión, sino como estímulo e inspiración. Para el turista, la diferencia vivificante se mantiene más frente al atosigamiento de lo mismo que frente a lo adulterado o falso. Vinculada a la demanda de autenticidad, una actitud hiperromántica podría ser utilizada contra el turismo, en la medida en que esa autenticidad no parece que pueda ser avalada hoy salvo muy excepcionalmente. La ética exige que el turista casi se preocupe más de su propio deseo y responsabilidad que de aquello que encontrará. Por esto decíamos, al comienzo, que la verdad última del turismo debe ser buscada mu- 
cho antes de la entrada en escena de la industria turística, en sus raíces antropológicas (Fennell, 2006: 14).

Mientras tanto, las posibilidades para una ética del turismo son enormes. Necesita una reflexión similar a la de Jonas en El principio de responsabilidad (Jonas, 1995), solo que en torno a un «Ensayo de una ética para la civilización turística». Abordaría múltiples temas, muchos de ellos en torno a la importancia acuciante de la sostenibilidad, debiéndose dedicar una esmerada atención a los aspectos más negativos, sobre todo del turismo de masas, siguiendo la divisa de dar prevalencia a los pronósticos malos sobre los buenos (Jonas, 1995: 71-72).

Quizás pudiera avanzarse, en el terreno de esa ética, una reflexión en torno a la exigencia de pasar desde la praxis de viajar-ver-estar de paso, a la praxis de viajar-visitar-participar. Toda visita exige que la atracción que experimenta sea vivida por el visitante como llena de respeto y amistad por aquel o aquello que hospitalariamente le recibe, sin abusar del estar de paso - como en un gigantesco no-lugar turístico (Augé, 2000: 83) -, tampoco por quien lo soporta. La ética del turismo sabe que el mundo no es algo que merezca simplemente ser visto - para eso valen las postales-, sino que merece ser visitado. Y el turista ya no querrá que le enseñen más postales, sino estar allí y participar. En el estar de visita, lo Otro y el Otro no serán meramente objetos/mercancías, ni el turista un molesto pero rentable cliente. Ya no se trataría del turismo como mero negocio, sino del ideal regulativo del turismo como devoción. Aparte de suponer una suerte de reservorio de enorme riqueza e infinitas posibilidades para una cierta desaceleración simbólica de los alienantes procesos de modernización, el turismo apela a la belleza y cultura seductoras del mundo, en su diversidad multicultural e intercultural y según los otros que lo habitan (Aime y Papotti, 2012). Decía Sloterdijk que

consecuentemente, en la Modernidad ya no recae en los metafísicos, sino en los geógrafos y en los marinos, la tarea de dibujar la nueva imagen del mundo: su misión es representar en imagen la última esfera. De todos los grandes cuerpos redondos, a la humanidad sin cubiertas solo puede importarle algo [...] su propio planeta. Los navegantes que dan la vuelta al mundo, los cartógrafos, los conquistadores, los comerciantes que recorren el mundo, incluso los misioneros cristianos y toda su retaguardia de colaboradores pro desarrollo, gentes que exportan buena voluntad, y de turistas que gastan dinero en experiencias por escenarios lejanos: todos ellos, vistos en su conjunto, se comportan como si hubieran comprendido que es la Tierra misma la que, tras la destrucción del cielo, tenía que asumir su función como última bóveda (Sloterdijk, 2010: 39). 
Sloterdijk no tiene razón del todo. La modernidad -y su crítica- sigue recayendo, si no en «los metafísicos», sí en los filósofos, en la medida en que, incluso si toda esa cosmovisión de los circunvaladores siguiera dependiendo de un deseo, finalmente quien mejor podría comprender sería el filósofo. A este respecto, la ética del turismo debe profundizar en las posibilidades de un turismo crecientemente reflexivo, abarcando desde la formación en los primeros niveles educativos hasta la elaboración de guías de viajes (Barthes, 2008: 125129), que sobre todo aspire a alcanzar, en el deseo de lo diverso, una experiencia centrada más en sí misma, en ultimísima instancia, que en los atributos de lo que encuentra o se le ofrece, es decir, en la propia inspiración que el viajero-turista desea. Se habrá comprendido, finalmente, que tampoco era imprescindible ir demasiado lejos, ¿o acaso no se puede ser turista en la propia ciudad? ¿No supondría ello haber aprendido de los otros turistas que la visitan, cuando nos preguntásemos, constatándoles admirados, qué ven ellos que yo no habría sido capaz de ver?

\section{A MODO DE CONCLUSIÓN}

Hemos partido de algunos rasgos antropológicos que, a nuestro juicio, subyacen al deseo de viajar — resumibles en el deseo de diferencia-, y que la actividad turística estaría en condiciones de satisfacer. Más allá de los aspectos que como sector productivo, de industria/negocio, medio de vida... implica el turismo, aquí nos ha interesado atender a su verdad última y a su sentido. Para ponerlos de manifiesto se ha ejercido una crítica sobre ciertos estereotipos que lo devalúan - desde el típico turista hasta el problema de la autenticidad en destino-, y se ha resaltado su potencia de excepcionalidad compensatoria, en tanto ofrece la posibilidad de que el turista experimente el cambio de perspectiva que busca, compensando la aceleración y escasez de exotismo de su vida cotidiana.

Finalmente, delineamos algunos de los rasgos de una ética del turismo, preocupada por la protección de lo real, lo local, del pasado... en nuestra era de la globalización, además de por la sensibilización ecológica, aunando responsabilidad y sostenibilidad, apuntando a un ideal regulativo del turismo que, en último término, se cifraría en que atendamos a la necesidad de formación para un turismo reflexivo y multicultural que solo puede brindarnos su vínculo con las humanidades. 


\section{BIBLIOGRAFÍA}

Agencia Valenciana de Turismo (2016). Agencia Rosebud: No me enseñes más postales. Comunitat Valenciana, Mediterráneo en vivo. [Archivo de vídeo.] Recuperado de: https://www.youtube.com/watch?v=_4 UnLU2RJ1 $J_{1}$ [Consultado el 14 de marzo de 2020].

Aime, Marco y Papotti, Davide (2012). L'altro e l'altrove. Antropologia, geografia e turismo. Torino: Einaudi.

Amirou, Rachid (1995). Imaginaire touristique et sociabilités du voyage. Paris: PUF.

Aramberri, Julio (2011). Turismo de masas y modernidad. Un enfoque sociológico. Madrid: Centro de Investigaciones Sociológicas.

Arcos Pumarola, Jordi (2016). Turismo cultural y patrimonio filosófico: un estado de la cuestión. International Journal of Scientific Managment Tourism, 2(3), 41-62.

Augé, Marc (1998). El viaje imposible. El turismo y sus imágenes. Barcelona: Gedisa.

Augé, Marc (2000). Los no-lugares. Espacios del anonimato. Una antropología de la sobremodernidad. Barcelona: Gedisa.

Babou, Isabel y Callot, Philippe (2009). Slow tourism, slow (r)évolution? Cahier Espaces, 100, 48-54.

Barthes, Roland (2008). Mitologías. México: Siglo XXI.

Baudrillard, Jean (1987). Cultura y simulacro. Barcelona: Kairós.

Baudrillard, Jean (1991). La transparencia del mal. Barcelona: Anagrama. Bauman, Zygmunt (2009). Ética postmoderna. Madrid: Siglo XXI.

Cohen, Erik (2005). Principales tendencias en el turismo contemporáneo. Política y Sociedad, 42(1), 11-24.

Conill, Jesús (Ed.) (2002). Glosario para una Sociedad intercultural. Valencia: Bancaja.

Diego, Estrella de (2014). Rincones de postales. Turismo y hospitalidad. Madrid: Cátedra.

Fennell, David A. (2006). Tourism ethics. Clevedon: Channel View Publications. 
Frenzel, Fabien, Koens, Ko y Steinbrink, Malte (2012). Slum tourism: Poverty, power and ethics. London: Routledge.

Gergen, Kenneth (2006). El yo saturado. Dilemas de identidad en el mundo contemporáneo. Barcelona: Paidós.

Heidegger, Martin (2016). Ser y tiempo. Madrid: Trotta.

Houllebecq, Michel (2002). Plataforma. Barcelona: Anagrama.

Jonas, Hans (1995). El principio de responsabilidad. Ensayo de una ética para la civilización tecnológica. Barcelona: Herder.

Lipovetsky, Gilles (1986). La era del vacío. Barcelona: Anagrama.

López-González, José L. (2019). El neuroturismo en la era de la aceleración social: una aproximación crítica a sus implicaciones éticas. En Cañada, Ernest y Murray, Iván (Eds.). Turistificación global. Perspectivas críticas en los análisis de turismo (145-160). Barcelona: Icaria.

MacCannell, Dean (1988). Turismo e identidad cultural. En Todorov, Tzvetan (Ed.). Cruce de culturas y mestizaje cultural (207-227). Madrid: Júcar.

MacCannell, Dean (2003). El turista. Una nueva teoría de la clase ociosa. Barcelona: Melusina.

Marquard, Odo (200o). Apología de lo contingente. Valencia: Institució Alfons el Magnànim.

Marquard, Odo (2001). Filosofía de la compensación. Escritos sobre antropología filosófica. Barcelona: Paidós.

Martínez Quintana, Violante (2017). El turismo de naturaleza: un producto turístico sostenible. Arbor, 193(785): a396. doi: http://dx.doi.org/10.3989/arbor.2017.785n3002.

Moira, Polyxeni, Mylonopoulos, Dimitrios y Kondoudaki, Aikatereni (2017). The Application of Slow Movement to Tourism: Is Slow Tourism a New Paradigm? Journal of Tourism and Leisure Studies, 2(2), 1-10. doi: 10.18848/2470-9336/CGP/vo2io2/1-10.

Moreno, César (2020). De ida y por principio: no sin Fenomenología. Terapia filosófica y mundo de la vida. Haser. Revista Internacional de Filosofía Aplicada, 11, 165-196. doi: 10.12795/HASER/2020.111.06 
Ortega y Gasset, José (2017). Conciencia, objeto y las tres distancias de éste (Fragmentos de una lección). En Obras completas II (203-208). Madrid: Taurus/Revista de Occidente.

Quinlan Cutler, Sarah y Carmichael, Barbara A. (2010). The dimensions of the tourist experience. En Morgan, Michale, Lugosi, Peter y Ritchie, J.R. Brent (Eds.). The Tourism and Leisure Experience: Consumer and Managerial Perspectives (3-26). Bristol: Channel View Publications. doi: 10.21832/9781845411503-004.

Rivera Mateos, Manuel (2012). Turismo responsable y relaciones interculturales en el contexto de la globalización. En Rodríguez García, Luis y Roldán Tapia, Antonio R. (Coord.). Interculturalidad: un enfoque interdisciplinar. I Jornada sobre investigación e innovación para la interculturalidad (181-205). Córdoba: Universidad de Córdoba.

Salazar, Noel B. (2005). Más allá de la globalización. La «glocalización» del turismo. Política y Sociedad, 42(1), 135-149.

Segalen, Victor (2017). Ensayo sobre el exotismo. Una estética de lo diverso. Madrid: La línea del horizonte.

Simmel, Georg (2001). El individuo y la libertad. Ensayos de crítica de la cultura. Barcelona: Península.

Sloterdijk, Peter (2010). En el mundo interior del capital. Para una teoría filosófica de la globalización. Madrid: Siruela.

Verdú, Vicente (2006). El estilo del mundo. La vida en el capitalismo de ficción. Barcelona: Anagrama. 
154 RECERCA · DOI: http://dx.doi.org/10.6035/Recerca.2020.26.1.7 · ISSN electrónico: 2254-4135 - pp. 134-153 